\title{
Influence of setting on unattended respiratory monitoring in the sleep apnoea/hypopnoea syndrome
}

\author{
P. Lloberes*, G. Sampol*, G. Levy*, D. Aristizabal*, T. Sagales", M. De la Calzada*, A. Roca*, \\ I. Cañas" ${ }^{\#}$ F. Morell*
}

Influence of setting on unattended respiratory monitoring in the sleep apnoealhypopnoea syndrome. P. Lloberes, G. Sampol, G. Levy, D. Aristizabal, T. Sagales, M. De la Calzada, A. Roca, I. Cañas, F. Morell. C ERS Journals Ltd 2001.

ABSTRACT: The high demand for full polysomnography and the better quality of sleep at home are the main reasons for performing home sleep studies. Home respiratory monitoring has been evaluated in several studies, but the influence of setting on the results of unattended respiratory monitoring has not been assessed to date.

Unattended monitoring of respiratory variables at home and in the sleep laboratory was conducted in 35 consecutive patients with suspected sleep apnoea/hypopnoea syndrome. Respiratory variables during sleep, rate of successful studies and patient preference were compared.

The data acquisition failure rate was $2.8 \%$ in the sleep laboratory and $5.7 \%$ at home. The mean difference between apnoea/hypopnoea indices (AHI) obtained from home and laboratory studies was $-\mathbf{0 . 2 1} \pm 8(95 \%$ confidence interval $3.27-2.84)$. Using the method comparison approach of Bland and Altman, the limits of agreement of the mean difference between $\mathrm{AHI}$ home and $\mathrm{AHI}$ laboratory were -16.7 and 17.1. No difference was observed between the studies in time spent in different body positions. When patients were asked where they would prefer to repeat the sleep study, $53 \%$ replied at home, $28 \%$ in hospital and $19 \%$ showed no preference.

It was concluded that the setting of unattended respiratory monitoring (home or sleep laboratory) influences neither the number of valid studies nor the results of the respiratory parameters measured; most patients, however, preferred home studies. Eur Respir J 2001; 18: 530-534.
*Servei de Pneumologia i " Servei de Neurofisiologia Clinica, Hospital General Vall d'Hebron, Barcelona, Spain.

Correspondence: P. Lloberes, Servei de Pneumologia, Hospital General Vall d'Hebron, Passeig Vall d'Hebron 119129, 08035 Barcelona, Spain. Fax: 34932746083

Keywords: Ambulatory monitoring respiratory variables sleep apnoea/hypopnoea syndrome unattended monitoring

Received: August 162000

Accepted after revision May 12001
Sleep apnoea/hypopnoea syndrome (SAHS) is a very common condition [1, 2]. Douglas et al. [3] showed that recording sleep electrophysiologically was of no diagnostic value in SAHS as the condition can be as accurately defined by apnoeas plus hypopnoeas per time in bed as per time asleep. These findings have been supported by the results of many studies comparing monitoring of respiratory variables with polysomnography (PSG), even in an unattended setting [4-20]. PSG is indicated when a discrepancy exists between clinical symptoms and negative results of respiratory monitoring or when other diseases causing daytime sleepiness are suspected. The number of patients requiring assessment of possible SAHS has led to long waiting lists in many sleep laboratories, and attention is increasingly focused on domiciliary sleep studies $[9,10,12,13$, $15,16,18,19]$. To the authors' knowledge, home unattended respiratory monitoring has exclusively been compared with full PSG and, in some cases, to the same portable equipment used simultaneously with PSG in the sleep laboratory. Owing to the high demand for full PSG studies in the sleep laboratory, the authors began to perform unattended respiratory monitoring of sleep, both in the laboratory and at home. In order to assess the influence of setting on the results of the studies, home and laboratory unattended monitoring of respiratory variables during sleep were compared in terms of the number of technically successful studies, home versus laboratory variability and patient preference.

\section{Material and methods}

\section{Study subjects}

Exclusion criteria for participation in the study were: residence outside the metropolitan area of Barcelona (>30-min drive), shift work, lack of transportation facilities, symptoms suggesting narcolepsy or periodic leg movement disorder, or psycho-physical handicap hindering performance of the home study. The study population consisted of 35 consecutive patients referred to the outpatient sleep clinic for clinically-suspected SAHS.

\section{Study design}

The study was performed prospectively with each patient undergoing two studies of respiratory 
variables during sleep on consecutive nights; the order (sleep laboratory and home) was randomized. A power calculation showed that 35 patients would be required, based on the following assumptions: a difference in apnoea/hypopnoea index (AHI) of $10 \pm 20$ [21], a failure rate of $10 \%$ and a statistical power $\geqslant 80 \%$ at a significance level of $5 \%$. The protocol was consistent with the principles of the Declaration of Helsinki [22]. Studies without $4 \mathrm{~h}$ of interpretable recording were regarded as technically unsatisfactory and ruled out. The minimum signals required to define an interpretable recording were oronasal flow, oximetry and one of the thoracic or abdominal bands.

Variables analysed from the respiratory recordings were: time of recording, AHI, mean and nadir arterial oxygen saturation $\left(\mathrm{Sa}_{\mathrm{a}} \mathrm{O}_{2}\right)$, cumulative percentage of time with $\mathrm{Sa}_{\mathrm{a}} \mathrm{O}_{2}<90 \%$ and percentage of time in different body positions (supine or lateral). After the performance of both studies, patients were required to answer a questionnaire on self-perception of sleep quality, subjective number of hours slept, number of awakenings and where they would prefer to have the study repeated.

\section{Methods}

The respiratory monitor used was Sibel-Home 300 (Sibel SA, Barcelona, Spain) which records nasal airflow using thermistors, respiratory effort (chest and abdomen gauges), snoring (microphone), body position and finger pulse-oximetry. The device had been validated with full PSG [20]. Both home and laboratory recordings were transferred to a computer by a technician the following morning and stored on the hard disk until analysis. The duration of each recording was used for analysis. The same physician scored the studies manually and was unaware of the patient's name or where the recording was performed. Apnoeas were defined as absence of oronasal airflow for $\geqslant 10 \mathrm{~s}$ and hypopnoeas as a discernible reduction in airflow for $\geqslant 10 \mathrm{~s}$ followed by a $\geqslant 3 \%$ reduction in $\mathrm{Sa}_{\mathrm{a}} \mathrm{O}_{2}$. The AHI was obtained by dividing the number of apnoeas plus hypopnoeas by the time of recording. SAHS was defined on the basis of an AHI $>10$ in the presence of at least two of the following clinical symptoms: snoring, witnessed apnoeas, nocturnal choking, nocturia, morning headaches, daytime somnolence and tiredness. These symptoms were evaluated by the physician in charge of the patients at an initial visit prior to the night study.

With respect to home studies, after arriving at the sleep laboratory at 20:00 h, patients were instructed in the use of the unattended device for $\sim 30 \mathrm{~min}$. A nurse placed bands on each patient's chest and abdomen and the microphone on the suprasternal notch, and explained how to position the thermistor and the pulse-oximeter. Patients took the monitor home in a bag and were told to switch it on upon going to bed, switch it off upon awakening and return it to the sleep laboratory the following morning.

Regarding sleep laboratory studies, the same nurse placed the sensors on the patients, switched on the monitoring device at 22:00 $\mathrm{h}$ and switched it off at $\sim 6: 30$ h. Both studies were unattended.

\section{Data analysis}

Agreement between the AHI obtained from home and sleep laboratory studies was assessed by the method of Bland and Altman [23]. Values were quoted as mean \pm SD and the significance of differences between means was assessed by a two-tailed t-test. Category comparisons were made with the Chisquared test. Pearson correlations between home and sleep laboratory AHI and home and laboratory 3\% desaturation rate were obtained.

\section{Results}

The mean age of the patients was $55.5 \pm 11.7$ yrs and mean body mass index was $29.1 \pm 3.1 \mathrm{~kg} \cdot \mathrm{m}^{-2}$. Two cases were lost due to failure in acquisition of the airflow signal (one at home, one in the laboratory) and one due to fuse failure at home. Thus, the failure rate was $2.8 \%$ at the laboratory and $5.7 \%$ at home. The overall failure rate was $8.57 \% \quad(95 \%$ confidence interval (CI) 1.80-23.06). Thirty-two patients had interpretable recordings in both home and sleep laboratory studies and were suitable for subsequent analysis $(91.5 \%)$.

The results of home and sleep laboratory studies showed no significant differences in any of the parameters studied except in the duration of recording, which was significantly higher in the sleep laboratory compared with home studies $(8.7 \pm 0.9$ and $7.7 \pm 0.7 \mathrm{~h}$, respectively, $\mathrm{p}<0.0001$ ) (table 1 ). No significant differences were observed between mean AHI from home and laboratory studies. The mean difference between home AHI and laboratory AHI was $-0.21 \pm 8.47(95 \% \mathrm{CI}$ of the mean difference -3.27-2.84; limits of agreement -16.7-17.1) (fig. 1). A highly

Table 1.-Respiratory parameters from unattended respiratory monitoring performed at home and in the sleep laboratory

\begin{tabular}{lcc}
\hline Parameters & \multicolumn{2}{c}{ Monitoring location } \\
\cline { 2 - 3 } & Home & Sleep laboratory \\
\hline Apnoeas* & $18.8 \pm 22.4$ & $18.5 \pm 22.4$ \\
Hypopnoeas* & $11.1 \pm 9.1$ & $12.7 \pm 11.7$ \\
AHI & $29.8 \pm 25$ & $30 \pm 26.5$ \\
Baseline $S_{\mathrm{a}, \mathrm{O}_{2}}$ & $96.1 \pm 1$ & $95.8 \pm 1$ \\
Mean $S \mathrm{a}, \mathrm{O}_{2}$ & $94.1 \pm 2.5$ & $93.8 \pm 2$ \\
Nadir $\mathrm{S}_{\mathrm{a}, \mathrm{O}_{2}}$ & $78.6 \pm 11$ & $80.6 \pm 5$ \\
Time in supine position \% & $42.7 \pm 25.7$ & $45.6 \pm 27$ \\
Time in lateral position \% & $52.2 \pm 26.7$ & $51.7 \pm 27$ \\
Hours of recording & $7.7 \pm 0.7$ & $8.7 \pm 0.9^{\#}$ \\
CT 90\% & $5.3 \pm 1.5$ & $6.2 \pm 11.6$ \\
Desaturations $>3 \% *$ & $20.9 \pm 19.5$ & $23.8 \pm 23.6$ \\
\hline
\end{tabular}

Data are presented as mean \pm SD. AHI: apnoea/hypopnoea index; $\mathrm{Sa}_{\mathrm{a}} \mathrm{O}_{2}$ : arterial oxygen saturation; CT $90 \%$ : cumulative percentage of time with $S_{\mathrm{a}, \mathrm{O}_{2}}<90 \%$. *: per hour; ${ }^{\#}$ : $\mathrm{p}<0.001$ when compared with home monitoring. 


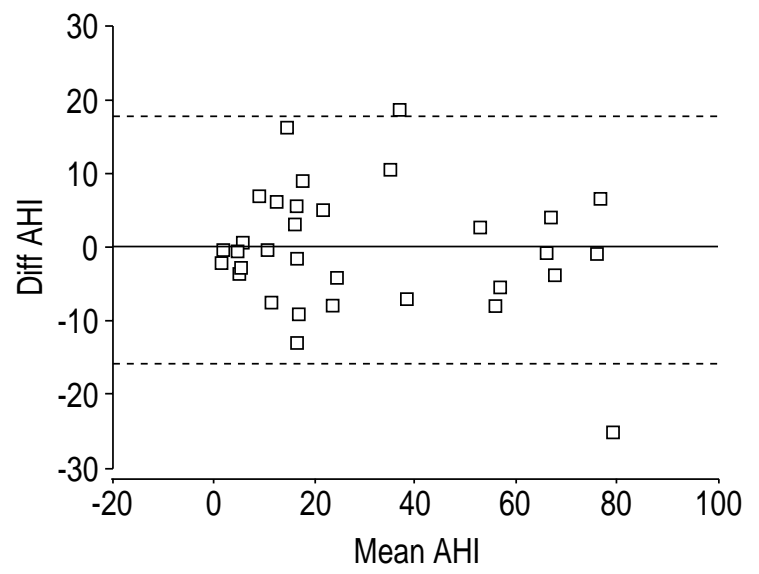

Fig. 1.-Difference between apnoea/hypopnoea index (AHI) in home and laboratory recordings (diff AHI) plotted against their mean (mean AHI). _ : the mean difference between both measurements; - - - - : the limits of agreement of the mean difference.

significant correlation was found between AHI obtained from both studies $(\mathrm{r}=0.97, \mathrm{p}<0.001)$ and between $3 \% S \mathrm{a}, \mathrm{O}_{2}$ desaturation index $(\mathrm{r}=0.95, \mathrm{p}<0.01$, fig. 2).

Table 2 shows the patients' self-reports of quality of sleep during both studies. No significant differences were found among the parameters studied when comparing both unattended studies. As shown, the proportions of patients having subjectively slept well, neither well nor badly, or badly were similar. The subjective estimation of time slept at home and in the laboratory was also similar $(5.6 \pm 1.5$ and $5.5 \pm 1.6$, respectively). When patients were asked where they would repeat the sleep study, 17 replied at home $(53 \%)$, nine $(28 \%)$ at the hospital and six $(19 \%)$ had no preference.

\section{Discussion}

The present study yielded three main results. First, unattended recording of respiratory variables during sleep proved to be an efficient procedure both at home

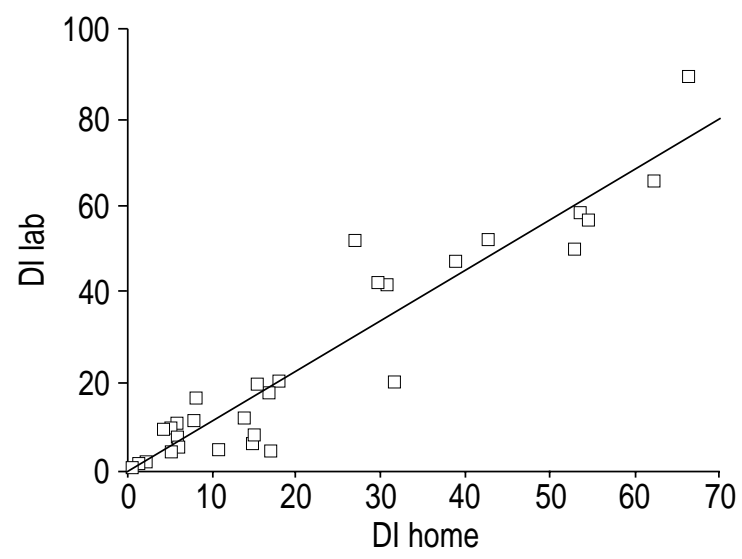

Fig. 2.-Correlation between $3 \%$ desaturation index recorded at home (DI home) and in the laboratory (DI lab).
Table 2. - Subjective evaluation of sleep quality at home and in the sleep laboratory

\begin{tabular}{lcc}
\hline & \multicolumn{2}{c}{ Study } \\
\cline { 2 - 3 } & Home & Sleep laboratory \\
\hline Hour slept $\mathrm{n}$ & $5.5 \pm 1.5$ & $5.6 \pm 1.6$ \\
Awakenings $\mathrm{n}$ & $3 \pm 1.4$ & $3.4 \pm 1.4$ \\
Slept well & $9(28)$ & $10(31)$ \\
Slept not well, but not badly & $18(56)$ & $17(53)$ \\
Slept badly & $5(16)$ & $5(16)$ \\
\hline
\end{tabular}

Data are presented as mean \pm SD or $\mathrm{n}(\%)$.

and in the sleep laboratory, with an acceptable failure rate. Secondly, the parameters recorded in the laboratory and at home showed no significant differences and, therefore, no significant influence of the setting on the results. Thirdly, more than half the patients stated they would rather repeat the study at home than in the sleep laboratory.

Numerous studies have been published on the efficacy of home sleep studies $[9,10,12,13,15,16$, $18,19]$, but none compared the same portable monitoring system in an unattended way at home and in the sleep laboratory. Most ambulatory devices have been tested in a laboratory setting with simultaneous attended full PSG monitoring rather than unattended as in the home setting. The present study's protocol permitted assessment of the performance of the equipment both in the home and the laboratory, thereby avoiding the confounding effects of a simultaneous montage, which is uncomfortable for the patient. Flemons and Remmers [18] found a systematic bias between home and laboratory studies using the "Snore Sat" device. The home Snore Sat respiratory disturbance index (Ssat RDI) was lower than the simultaneous RDI (Ssat) or AHI (full PSG) performed at the sleep laboratory. The mean difference between simultaneous Ssat RDI and home Ssat RDI was 9.3 (limits of agreement 40.8 and -22.2). The authors believed that the difference between home and laboratory RDI probably depended on body position, and possibly less sleep disruption at home, resulting in fewer sleep onset hypopnoeas. A better agreement was found between home and laboratory AHI when both studies were unattended (mean difference $-0.21 \pm 8.47(95 \%$ CI $-3.27-2.84)$ and no difference in the percentages of time in different body positions. In contrast, during full PSG in the sleep laboratory, patients usually spent more time in the supine position than they did at home, as demonstrated by BALLESTER et al. [24] and suggested by FLEMONS and REMMERS [18]. PARRA et al. [19] studied the validity of a portable monitor of respiratory variables used in a home setting for the diagnosis of SAHS. In 50 and 39 patients respectively, the portable monitor was set-up with and without a technician's help. Although 10\% of studies with an individual set-up required repeating, both of the domiciliary modalities (with and without a technician's intervention) were three times more cost-effective than full PSG. It was found that laboratory readings were significantly longer than home studies. In fact, in laboratory studies, recordings 
began at 22:00 $\mathrm{h}$ and were stopped at $06.30 \mathrm{~h}$ due to staff time schedules, while at home, patients switched the device on and off at will, resulting in a shorter recording time. The patients' self-perception of time asleep was significantly less than the actual recorded time. This could imply that the AHI obtained from recording time, not from sleeping time, underestimates the true AHI. However, when comparing subjective and polysomnographically determined sleep in SAHS patients, MCCALL et al. [25] reported that patients underestimate the time of sleep. In addition, Douglas et al. [3] showed that SAHS can be as accurately defined by apnoeas+hypopnoeas per time in bed as per time asleep.

Portable unattended recording devices are potentially subject to data loss or distortion because of equipment malfunction, sensor disconnection, technologist error, patient or family error or interference, power surges or loss, damage in transit, phone line interference during modem transfer, and error during playback. In the present study, three cases were lost due to failure in data acquisition (human failure in two cases and fuse failure in one). The failure rate was $2.8 \%$ and $5.7 \%$ for laboratory and home studies, respectively. The authors believe that the fuse failure at home may also have occurred in the laboratory, and thus, the failure rate could be considered equal in the two settings. Overall, a failure rate of $8.5 \%$ was obtained, similar to that described by PARRA et al. [19] and less than that reported by ANCOLI-ISRAEL et al. [12]. REDLINE et al. [26] reported a 5.3\% failure rate when performing unattended full PSG at home, although the set-up of the equipment was made during an evening home visit by a technician.

Another interesting observation was patient preference, if a repeat study was necessary. Seventeen patients $(53 \%)$ replied that they would rather be at home, nine in hospital $(28 \%)$ and six had no preference $(18.7 \%)$. Some previous studies have addressed this question and found different opinions. For some patients, sleeping alone in a laboratory bed can make them feel uncomfortable, anxious, and under observation. In such cases, home recording affords improved comfort and familiarity during studies conducted at appropriate sleep-wake cycle times, with first-night effects minimized. In contrast, other patients may worry more if they are studied without medical supervision [27-29].

It is concluded that in patients with suspected sleep apnoea/hypopnoea syndrome, the setting of unattended respiratory monitoring (home or sleep laboratory) influences neither the number of valid studies nor the results of respiratory parameters measured; most patients, however, prefer home studies.

\section{References}

1. Young T, Palta M, Dempsey J, Skatrud J, Weber S, Badr S. The occurrence of sleep-disordered breathing among middle-aged adults. N Engl J Med 1993; 328: 1230-1235.

2. Esnaola S, Duran J, Rubio R, Iztueta A. Prevalence of obstructive sleep apnoea in the male population of
Vitoria-Gasteiz (Spain). Eur Respir J 1995; 8: Suppl. 19, 436.

3. Douglas NJ, Thomas S, Jan MA. Clinical value of polysomnography. Lancet 1999; 339: 347-350.

4. Whittle AT, Finch SP, Mortimore IL, MacKay TW, Douglas NJ. Use of home sleep studies for the diagnosis of the sleep apnoea/hypopnoea syndrome. Thorax 1997; 52: 1068-1073.

5. Chesson AL Jr, Ferber RA, Fry JM, et al. The indications for polysomnography and related procedures. Sleep 1997; 20: 423-487.

6. Carrasco O, Montserrat JM, Lloberes P, et al. Visual and different automatic scoring profiles of respiratory variables in the diagnosis of sleep apnoea/hypopnoea syndrome. Eur Respir Dis 1996; 9: 125-130.

7. Lloberes P, Montserrat JM, Ascaso A, et al. Comparison of partially attended night-time respiratory recordings and full PSG in patients with suspected sleep apnoea/hypopnoea syndrome. Thorax 1996; 51: 1043-1047.

8. Godfrey CW, Man BS, Bhavandeep BS. Validation of a portable sleep apnoea monitoring device. Chest 1995; 108: 388-393.

9. Esnaola S, Duran J, Infante-Rivard C, Rubio R, Fernández A. Diagnostic accuracy of a portable device (Mesam IV) in suspected obstructive sleep apnoea. Eur Respir J 1996; 9: 2597-2605.

10. Emsellem HA, Corson WA, Rappaport BA, Hackett S, Smith LG, Hausfeld JN. Verification of sleep apnoea using a portable sleep apnoea screening device. South Med J 1990; 83: 748-752.

11. Redline S, Tosteson T, Boucher MA, Millman R. Measurement of sleep-related breathing disturbance in epidemiologic studies. Assessment of the validity and reproducibility of a portable monitoring device. Chest 1991; 100: 1281-1286.

12. Ancoli-Israel S, Kripke DF, Mason W, Messin S. Comparisons of home sleep recordings and polysomnograms in older adults with sleep disorders. Sleep 1981; 4: 283-291.

13. Gyulay S, Gould D, Sawyer B, Pond D, Mant A, Saunders N. Evaluation of a microprocessor-based portable home monitoring system to measure breathing during sleep. Sleep 1987; 10: 130-142.

14. Svanborg E, Larsson H, Carlsson-Nordlander B, Pirskanen R. A limited diagnostic investigation of sleep apnoea syndrome. Oximetry and static charge sensitive bed. Chest 1990; 98: 341-345.

15. Stoohs R, Guilleminault C. Mesam 4: an ambulatory device for the detection of patients at risk for obstructive sleep apnoea syndrome (OSAS). Chest 1992; 101: 1221-1227.

16. Coppola M, Lawee D. Management of obstructive sleep apnoea syndrome in the home. Chest 1993; 104: 19-25.

17. Kiely JL, Delahunty C, Matthews S, McNicholas WT. Comparison of a limited diagnosis system with polysomnography in the diagnosis of obstructive sleep apnoea. Eur Respir J 1996; 9: 2360-2364.

18. Flemons WW, Remmers JE. The diagnosis of sleep apnoea: questionnaires and home studies? Sleep 1996; 19: Suppl. 10, S243-S247.

19. Parra O, Garcia-Esclasans N, Montserrat JM, et al. Should patients with sleep apnoea/hypopnoea syndrome be diagnosed and managed on the basis of home sleep studies? Eur Respir J 1997; 10: 17201724. 
20. Ballester E, Solans M, Vila X, et al. Evaluation of a portable device for detecting apnoeas and hypopnoeas in subjects from a general population. Eur Respir $J$ 2000; 16: 123-127.

21. Ballester E, Badia JR, Hernandez L, et al. Evidence of the effectiveness of continuous positive airway pressure in the treatment of sleep apnea/hypopnea syndrome. Am J Respir Crit Care Med 1999; 159: 495-501.

22. World Medical Association Declaration of Helsinki. Recommendations guiding physicians in biomedical research involving human subjects. JAMA 1997; 277: 925-926.

23. Bland JM, Altman DG. Statistical methods for assessing agreement between two methods of clinical measurement. Lancet 1986; 1: 307-310.

24. Ballester E, Torrego A, Farre R, et al. Sleep lab versus home recording of body posture during sleep. Am J Respir Crit Care Med 1999; 159: A795.
25. McCall WV, Turpin E, Reboussin DR, Edinger JD, Haponik EF. Subjective estimates of sleep differ from polysomnographic measurements in obstructive sleep apnoea patients. Sleep 1995; 18: 646-650.

26. Redline S, Sanders MH, Lind BK, et al. Methods for obtaining and analyzing unattended polysomnography data for a multicenter study. Sleep 1998; 21: 759 767.

27. Sharpley AL, Solomon RA, Cowen PJ. Sleep stability with home sleep recording and automatic sleep stage analysis. Sleep 1990; 13: 538-540.

28. Sharpley AL, Solomon RA, Cowen PJ. Evaluation of first night effect using ambulatory monitoring and automatic sleep stage analysis. Sleep 1988; 11: 273276.

29. Middelkoop HAM, Neven AK, Van Weterin HF. No significant night-to-night variability of home recorded apnoeas in 22 subjects with suspected obstructive sleep apnoea syndrome. J Amb Monit 1993; 6: 235-241. 